Session FB1-2

\title{
Flow Pattern Phenomena Incorporated into a Model for Pressure Losses in Air- Water Heterogeneous Mixture Flow in Horizontal Minichannels
}

\author{
Chengyi Ma and Jerry K. Keska \\ Mechanical Engineering Department \\ University of Louisiana at Lafayette \\ Lafayette, LA 70504, USA
}

\begin{abstract}
Many electronic and mechanical systems have very precise temperature requirements which necessitate the presence of cooling or heating systems as high-standard thermal protection. Though many advances have been made in the development of such systems, new and effective systems, which can provide high heat intensity and geometrical size limitation, are still needed. One such system can be accomplished by using compact, two-phase heat exchangers which remove large amounts of heat by incorporating phase transition. The development of compact heat exchangers requires fundamental advancements in many areas, including fluid dynamics of two-phase flow. This, in turn, requires the development of a comprehensive mathematical model of two-phase flow incorporating flow pattern phenomena. Consequently, the final question becomes how to detect and measure flow patterns. Currently, the only methods that are used are qualitative, based solely on visual observations, which make the process extremely subjective and dependent on both the observer's abilities and the properties of the experimental system. Because flow pattern phenomena are so important and challenging, any attempt to quantitatively and objectively determine them would be considered advancement in the right direction.

The paper presents the results of experimental research on the incorporation of flow pattern phenomena into a mathematical model of pressure losses in the two-phase flow of a heterogeneous mixture of air and water in a horizontal square channel $(6.35 \mathrm{~mm}$ in size). The experimental system that was used consisted of hydraulic and electrical subsystems, where the mixture's dynamic in-situ parameters were measured. The generated results allowed the flow pattern coefficient to be obtained, which, when incorporated into the pressure loss model, significantly reduced the differences between experimental and predicted values.
\end{abstract}

\section{Introduction}

Many electronic and mechanical systems have very precise temperature requirements which necessitate the presence of cooling or heating systems as high-standard thermal protection. Though many advances have been made in the development of such systems, new and effective systems, which can provide high heat intensity and geometrical size limitation, are still needed. One such system can be accomplished by using compact, two-phase heat exchangers which remove large amounts of heat by incorporating phase transition. The development of compact heat exchangers requires fundamental advancements in many areas, including fluid dynamics of two-phase flow.

Proceedings of the 2009 ASEE Gulf-Southwest Annual Conference

Baylor University

Copyright () 2009, American Society for Engineering Education 
In industrial applications, there are a wide variety of two-phase flows that are possible. In this thesis, however, the term "two-phase flow" indicates a heterogeneous mixture flow of air and water in minichannels. There are significant differences in the flow phenomena between single-phase flow and two-phase flow. These differences are the result of the presence of different velocities for different phases. They are also the consequence of other parameters (such as spatial concentration) that impact both energy consumption models and flow patterns in two-phase flow. The energy that is used in two-phase flow is proportional to the length pressure gradients or the pressure losses. Both of these are influenced by many independent parameters such as mixture velocity, concentration, and flow patterns. Unfortunately, the existing mathematical models do not incorporate flow pattern phenomena. This causes significant differences (reaching sometimes a few hundred percent) between the measured and the simulated values. Because two-phase flow is used so often in industrial applications, these current, problematic models are far from satisfactory.

Attempting to incorporate flow patterns into a mathematical model is a critical and challenging process. The determination of flow pattern phenomena is extremely subjective and ambiguous. It relies primarily on the researcher's visual observation skills and judgment, and it cannot cover the entire range of velocities and concentrations. Before 1990, most of the research focusing on twophase flow used superficial parameters. Most likely, this was due to difficulties in measuring mixture concentration. More recently, however, more and more research in the field uses in-situ parameters such as velocity and concentration. These new studies also include models for the pressure gradient and other dynamic phenomena in two-phase flow of a heterogeneous mixture. This reduces the differences partially. Flow patterns, however, which are the most dynamic and subjective phenomena in two-phase flow, have yet to be satisfactorily incorporated into mathematical models. One possible solution to this problem involves the incorporation of flow patterns by using the flow pattern coefficient. This allows for the incorporation of the flow pattern coefficient without having to measure it.

The paper presents the results of experimental research on the incorporation of flow pattern phenomena into a mathematical model of pressure losses in the two-phase flow of a heterogeneous mixture of air and water in a horizontal square channel $(6.35 \mathrm{~mm}$ in size). The generated results allowed the flow pattern coefficient to be obtained, which, when incorporated into the pressure loss model, significantly reduced the differences between experimental and predicted values.

\section{Background}

The pressure drop in a two-phase flow channel can be predicted by the HEM (homogeneous equilibrium mixture) model. The pressure drop is caused by the acceleration, friction, and gravity in the channel. The method to measure the pressure drop in single-phase flow is to apply Darcy equation. However, when it comes to the measurements of pressure drop in two-phase flow, many researchers use Lockhart-Martinelli ${ }^{1}$ equations to predict the pressure drop. The two-phase flow multipliers, $\phi_{l}^{2}$ and $\phi_{g}^{2}$, are calculated in terms of the Martinelli parameters $X^{2}$, which can be defined as:

$X^{2}=\frac{\Delta p_{l}}{\Delta p_{g}}$.

The multipliers can be expressed as follows:

Proceedings of the 2009 ASEE Gulf-Southwest Annual Conference Baylor University

Copyright () 2009, American Society for Engineering Education 
$\phi_{\mathrm{g}}^{2}=1+C X+X^{2}$

and

$\phi_{1}^{2}=1+\frac{C}{X}+\frac{1}{X^{2}}$.

Lee and Lee $^{2}$ measured the pressure drop of a gas-liquid flow in minichannels with the gap between the upper and lower plates of each channel ranging between $0.4 \mathrm{~mm}$ and $4 \mathrm{~mm}$. The superficial velocities of the air and water were $0.03-2.39 \mathrm{~m} / \mathrm{s}$ and $0.05-18.7 \mathrm{~m} / \mathrm{s}$, respectively. The objective of the experiment was to modify the factor $\mathrm{C}$ in order to improve the Lockhart-Martinelli correlations. One of the correlations was proposed by Lowry and Kawaji ${ }^{3}$ and Wambsganss et al. ${ }^{4}$ :

$\mathrm{C}=A \lambda^{q} \psi^{r} \mathrm{Re}^{s}$

where $\operatorname{Re}$ is the Reynolds number of the liquid and $\lambda$ and $\psi$ are defined as:

$\lambda=\frac{\mu_{\mathrm{L}}^{2}}{\rho_{L} \sigma D}$ and

$\psi=\frac{\mu_{L} U}{\sigma}$

where $\mu_{L}$ is the viscosity of liquid, $\sigma$ is the surface tension, and $\mathrm{U}$ is the total superficial velocity. A, $\mathrm{q}, \mathrm{r}$, and s can be determined by whether the mixture flow is laminar or turbulent.

Triplett et al. ${ }^{5}$ investigated the pressure drop of two-phase flow in minichannels with hydraulic diameters of $1.09 \mathrm{~mm}$ and $1.49 \mathrm{~mm}$. Zhao and $\mathrm{Bi}^{6}$ described pressure drop models for single-phase flow and for two-phase flow based on the experimental data in vertical triangular channels with hydraulic diameters of $0.866 \mathrm{~mm}, 1.443 \mathrm{~mm}$, and $2.886 \mathrm{~mm}$, and with superficial air velocity (varying from 0.1 to $100 \mathrm{~m} / \mathrm{s}$ ) and water velocity (varying from 0.08 to $6 \mathrm{~m} / \mathrm{s}$ ). Keska and Wang ${ }^{7,8}$ proposed another model for the pressure drop equation by using a flow pattern coefficient to minimize the difference between theoretical and experimental values. Keska and Simon ${ }^{9,10}$, incorporated the flow pattern phenomena into the study of an advanced micro-cooling system where a new two-phase flow model was built and the pressure drop could be expressed thusly:

$\Delta P=\frac{d P}{d L} \Delta L$.

The frictional pressure gradient of a two-phase flow mixture was expressed as a superposition of two individual pressure drops that are a result of the gas and liquid components:

$\left.\frac{\Delta P}{\Delta L}\right|_{m}=\left.\frac{\Delta P}{\Delta L}\right|_{l}+\left.\frac{\Delta P}{\Delta L}\right|_{g}$

In-situ overall spatial concentration $\left(\mathrm{c}_{\mathrm{v}}\right)$ was used in this equation in order to modify the theoretical frictional pressure loss of the mixture. According to Darcy's equation, the energy loss $h$ can be expressed as follows:

$h=\frac{f \cdot \Delta L}{D} \frac{v^{2}}{2 g}=\frac{\Delta P}{\rho g}$;

$\frac{\Delta P}{\Delta L}=\frac{f \rho v^{2}}{2 D} ;$ and

$\Delta P=\frac{\Delta L}{2 D}\left[f_{g} v_{g}^{2} \rho_{g}\left(1-c_{v}\right)+f_{l} v_{l}^{2} \rho_{l} c_{v}\right]$. 
When the experimental pressure drop results are compared to the calculations using the theoretical pressure gradients (with flow conditions for given in-situ concentrations and velocities for the various flow patterns) significant differences between the theoretical and experimental results can be observed. By incorporating a flow pattern coefficient into the equation with in-situ component velocities, friction coefficients, and in-situ concentration, the difference is reduced significantly. The modified equation can be expressed as:

$$
\Delta P_{\text {tested }}=\frac{\Delta L}{2 D}\left[f_{g} v_{g}^{2} \rho_{g}\left(1-c_{v}\right)+f_{l} v_{l}^{2} \rho_{l} c_{v}\right] F p \text {. }
$$

It is clear that the flow pattern coefficient Fp will significantly impact the accuracy of the pressure drop results. The previous model proposed by Keska and Wang ${ }^{7,8}$ was presented by using statistics packages to minimize the differences. The correlation yields:

$\ln F p=11.3-2.88 \ln \left(\frac{v_{a}}{v_{w}}\right)+2.33 \ln \left(\frac{1-c_{v}}{c_{v}}\right)$.

Keska $^{11}$ then produced a more universal equation based on the nondimensssional analysis for a heterogeneous mixture flow of gas and water in a horizontal minichannel. The improved flow pattern coefficient, which was developed by using in-situ parameters (such as the in-situ mixture concentration and velocity, mixture kinematic viscosity, and channel diameter), can be written as:

$F p=\frac{1}{5000}\left(\frac{v_{m}}{v_{m}}\right)^{2}\left(c_{v}\right)^{4} D^{2}$.

From the experimental results involved with $\mathrm{Fp}$, the cumulative errors can be reduced by up to $94 \%$. The goal of this research is to conduct experimental work on a two-phase air-water mixture flow for a horizontal channel and then, based on that data, find the values for experimental constants in the mathematical model.

\section{Experimental Research}

The system for a horizontal, two-phase flow experiment is composed of a flow channel section as well as capacitive and resistive concentration sensor systems for computer-aided experimentation. The flow channel section consists of a transparent minichannel with a cross-section of $6.35 \mathrm{~mm} \mathrm{X}$ $6.35 \mathrm{~mm}$. The pressure, flow rate, capacitive, resistive, and film thickness sensors are installed separately in the minichannel. After the completion of preliminary tests and calibrations on the hydraulic and electronic parts, the system is ready for the experiment. The pressure sensors are included and connected on the prototype boards. An automatic calibration procedure is used to calibrate both the capacitive and the resistive systems so they can measure in-situ concentration. All of the data are collected by the DAQ system. After the initial data are taken from LabVIEW ${ }^{12}$ for calibration, the main data are then collected and saved into a text file. This is then transferred into a spreadsheet for further analysis. Each run of the experiment is saved in one worksheet of the spreadsheet. The calibration curve is then applied in order to analyze and receive appropriate parameters. A stroboscope is used in the system in order to "freeze" the mixture flow image and observe the flow pattern in the minichannel. The flow patterns observed in the experiment are bubble, slug, annular/slug, and annular flow. 

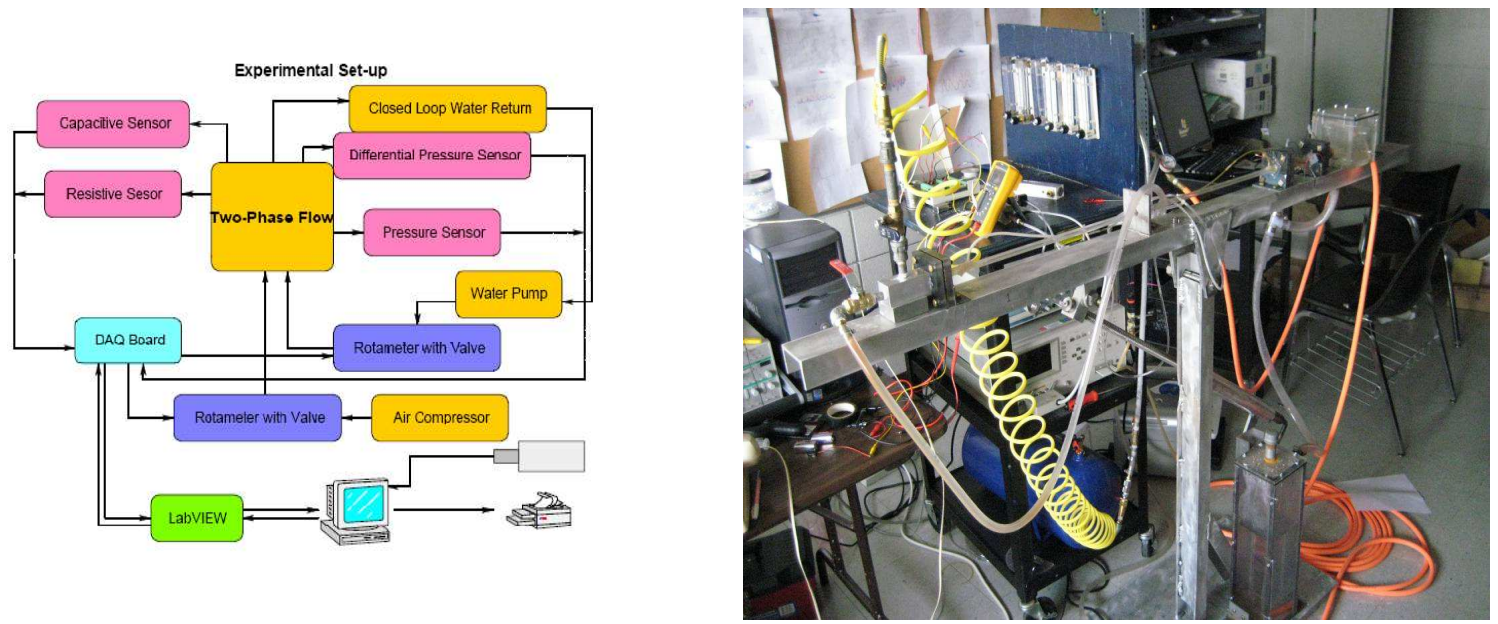

Figure 1. Set-up of the Experimental Two-

Figure 2. View of the Computer-aided Phase Flow System

Experimentation System for Two-Phase Mixture Flow in Horizontal Square Channel

\section{Experimental Data and Analysis}

Due to the calculation of velocities, the two different mixture velocities are the result of two sets of assumptions. The first velocity, $\mathrm{v}_{\mathrm{m} 1}$, is calculated under the assumption that the mass flow of the mixture is equal to the sum of masses of air and water. Another velocity, $\mathrm{v}_{\mathrm{m} 2}$, is calculated under the assumption that the mixture volume flowrate is equal to the sum of the air and the water volume flowrates. Both of the mixture velocities are important. They are incorporated with the data in order to analyze, compare, and determine which one can more accurately describe the flow conditions of the two-phase flow in the minichannel. Results indicate that $\mathrm{v}_{\mathrm{m} 2}$ from the volume equilibrium assumption gives us the better prediction. Therefore, the mixture velocity used in the flow pattern coefficient will be $\mathrm{v}_{\mathrm{m} 2}$.

The conducted experiments - for steady-state conditions in the full range of concentrations (0-1) and mixture velocities $(0-56 \mathrm{~m} / \mathrm{s})$, using in-situ parameters, and taking data simultaneously for air- water heterogeneous mixture flow in the horizontal minichannel-indicate that the used two concentration measurement systems are concomitant (Figure 3). The characteristics of water and air velocities, as a function of concentration, are shown in Figure 4. The air velocity is always higher than the water velocity and it increases as the concentration decreases.

Figure 5(a) shows the correlation between the mixture velocity and concentration. Two different velocities $\left(\mathrm{v}_{\mathrm{m} 1}\right.$ and $\left.\mathrm{v}_{\mathrm{m} 2}\right)$ are shown. Both of the mixture velocities decrease as the concentration increases. Likewise, the correlations have a hyperbolic character.

Figure 5(b) documents the correlations of the pressure drop as a function of the mixture velocities $\left(\mathrm{v}_{\mathrm{m} 1}\right.$ and $\left.\mathrm{v}_{\mathrm{m} 2}\right)$. The pressure drop increases as the mixture velocity increases. The characteristic of the first velocity $\left(\mathrm{v}_{\mathrm{m} 1}\right)$, however, shows a significantly higher consistency than the characteristic of the second velocity $\left(\mathrm{v}_{\mathrm{m} 2}\right)$. The three-dimensional view of the pressure drop, as a function of mixture velocity and concentration, is shown is Figure 6. 


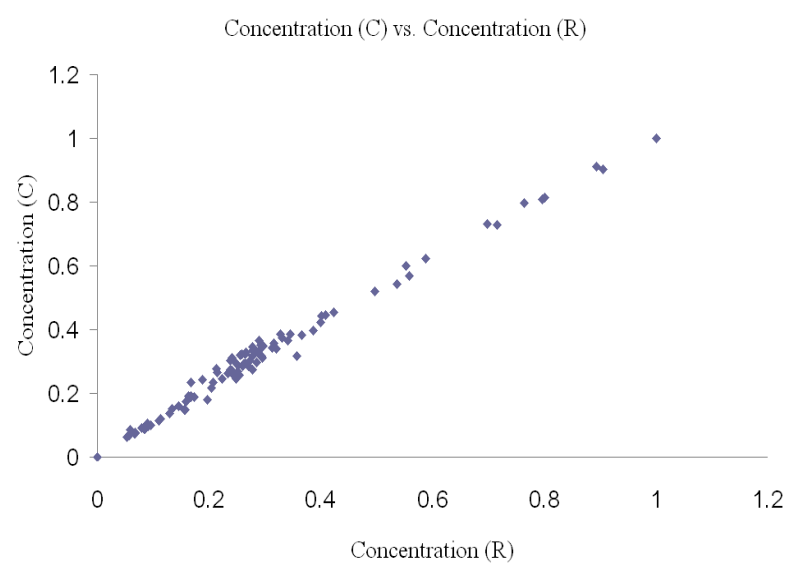

Figure 3. Concentration from Capacitive Sensor vs. Concentration from Resistive Sensor

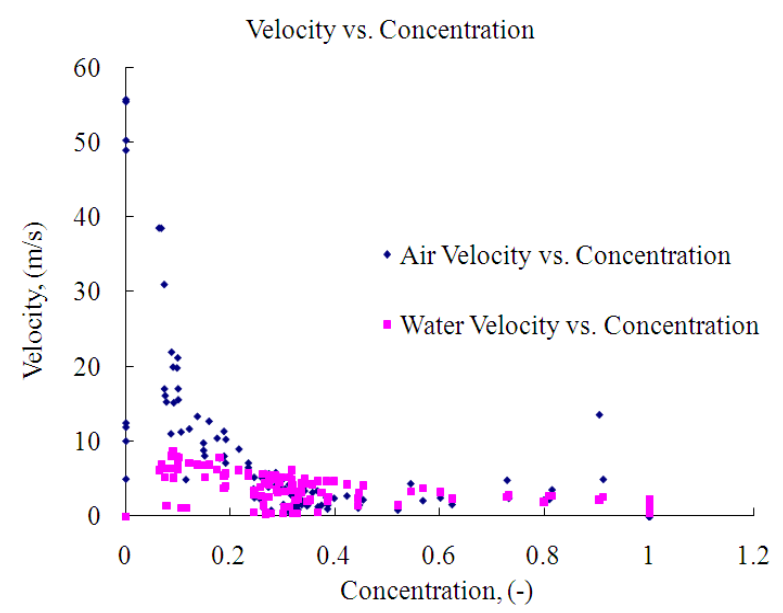

Figure 4. Water and Air Velocities vs. Concentration

Figure 5(c) illustrates pressure drop versus concentration, where the laminar and turbulent flow is distinguished by a Reynolds number. The pressure drop declines as the concentration increases.

Figures 5(d) and 5(e) show the correlation between the experimental and theoretical values of pressure drop for mixture velocity $\mathrm{v}_{\mathrm{m} 1}$ and $\mathrm{v}_{\mathrm{m} 2}$. Significant differences are observed in those graphs, which are caused by flow patterns, which greatly change the values of the pressure drop in comparison to the calculated values.

It is always advantageous to compare experimental results with a well known characteristic. In this case, this is the Moody's diagram that shows the characteristic of the friction factor versus the Reynolds number. The friction factor can be calculated from the experimental data as shown in Figure 5(f) and when this is placed in relationship to the Reynolds number, it produces very consistent characteristics.

The most important problem in two-phase heterogeneous mixture flow, however, is to overcome the lack of a mathematical model that can generate a reasonable difference between experimental data and simulated data including the length pressure gradient. Recognizing that improvement in this matter is impossible without incorporating flow pattern phenomena, Keska et al. ${ }^{5,6,7,8}$ developed a mathematical model for length pressure gradient as a function of in-situ parameters (mixture velocity, mixture viscosity, concentration, and flow pattern coefficient). Consequently, the flow pattern coefficient $(\mathrm{Fp})$ is the key factor in reducing the errors between these two pressure drop gradient values (theoretical and tested values). The Fp is defined as:

$F p=\frac{\left(\frac{\Delta P}{\Delta L}\right)_{\text {tested }}}{\left(\frac{\Delta P}{\Delta L}\right)_{\text {theoretical }}}$.

From the equation above, it can be observed that $\mathrm{Fp}$ is a dimensionless factor. After the application of a dimensionless analysis, this results in the following expression:

$F p=\left(\frac{v_{g}}{v_{l}}\right)^{c 1}\left(\frac{1-c_{v}}{c_{v}}\right)^{c 2}\left(\frac{v_{l}}{v_{g}}\right)^{c 3} c_{4}$.

Proceedings of the 2009 ASEE Gulf-Southwest Annual Conference Baylor University 
Based on the experimental data from Keska et al. ${ }^{5,6,7,8}$, the equation can be further simplified by finding the constants $\mathrm{c}_{4}, \mathrm{c}_{2}$ and $\mathrm{c}_{3}$, which gives the following:

$$
F p=\exp (11.3)\left(\frac{v_{a}}{v_{w}}\right)^{-2.88}\left(\frac{1-c_{v}}{c_{v}}\right)^{2.33} \text {. }
$$

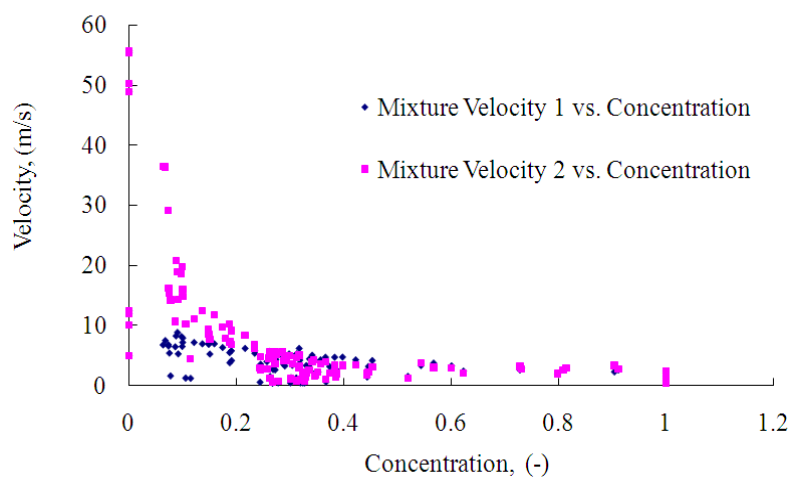

(a)

Pressure Drop vs. Concentration

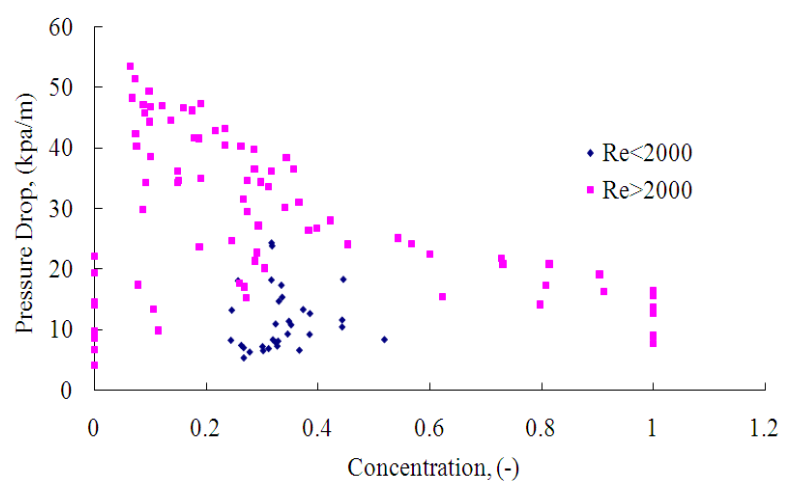

(c)

Tested Pressure Drop vs. Calculated Pressure Drop

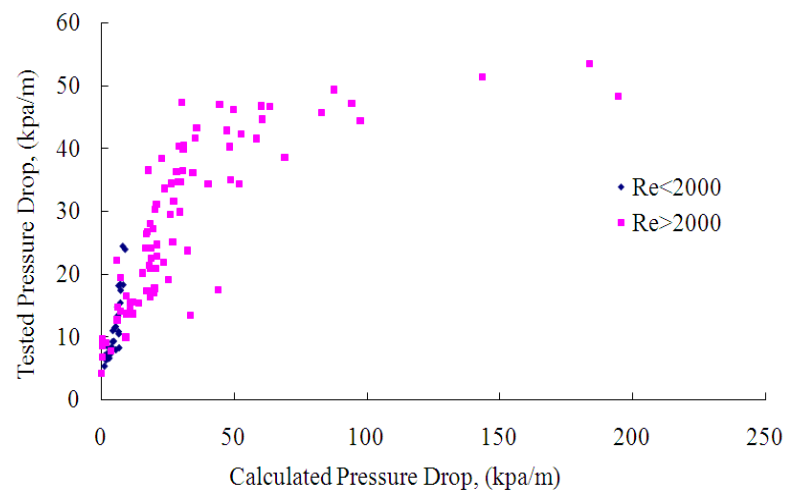

(e)
Pressure Drop vs. Mixture Velocity

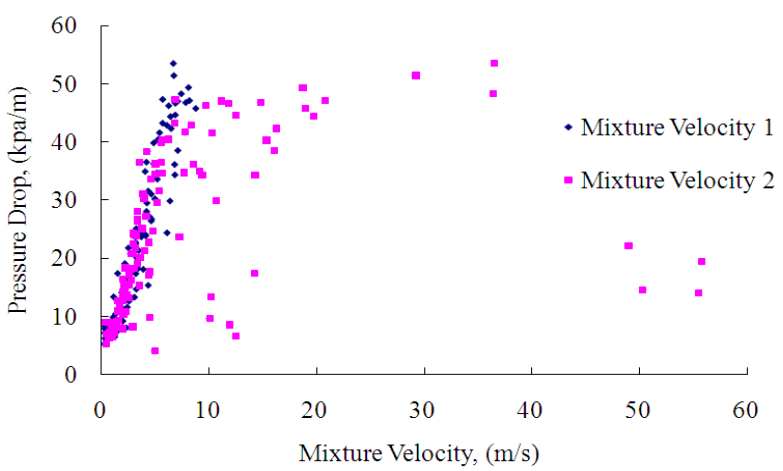

(b)

Tested Pressure Drop vs. Calculated Pressure Drop

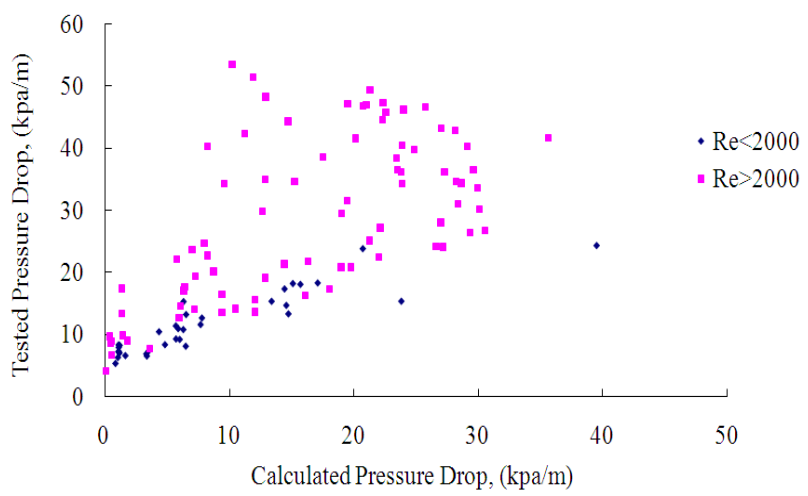

(d)

Friction Factor vs. Reynolds Number

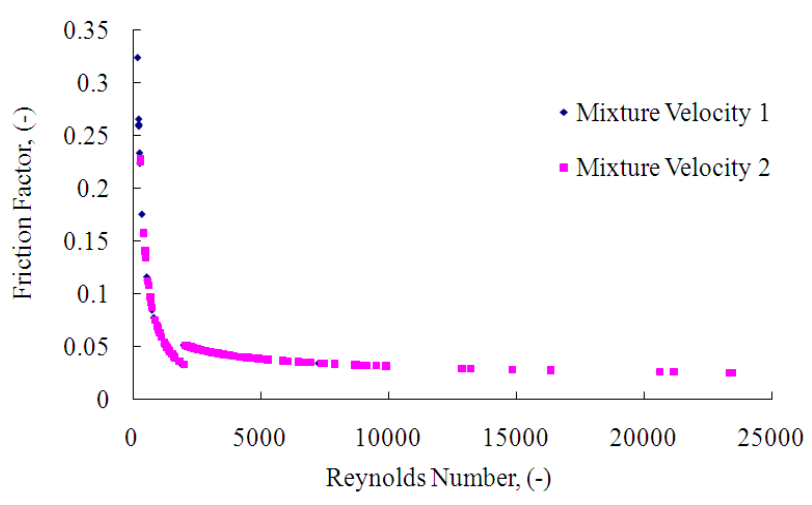

(f)

Figure 5. Experimental Result Analysis in Two-Dimensional View

(a) Mixture Velocities vs. Concentration (b) Pressure Drop vs. Mixture Flow Velocities (c)

Pressure Drop vs. Concentration (d) Tested Pressure Drop vs. Calculated Pressure Drop for v $\mathrm{m}_{1}$ (e) Tested Pressure Drop vs. Calculated Pressure Drop for $v_{m 2}$ (f) Friction Factor vs. Reynolds Number

Proceedings of the 2009 ASEE Gulf-Southwest Annual Conference Baylor University

Copyright $\odot$ 2009, American Society for Engineering Education 

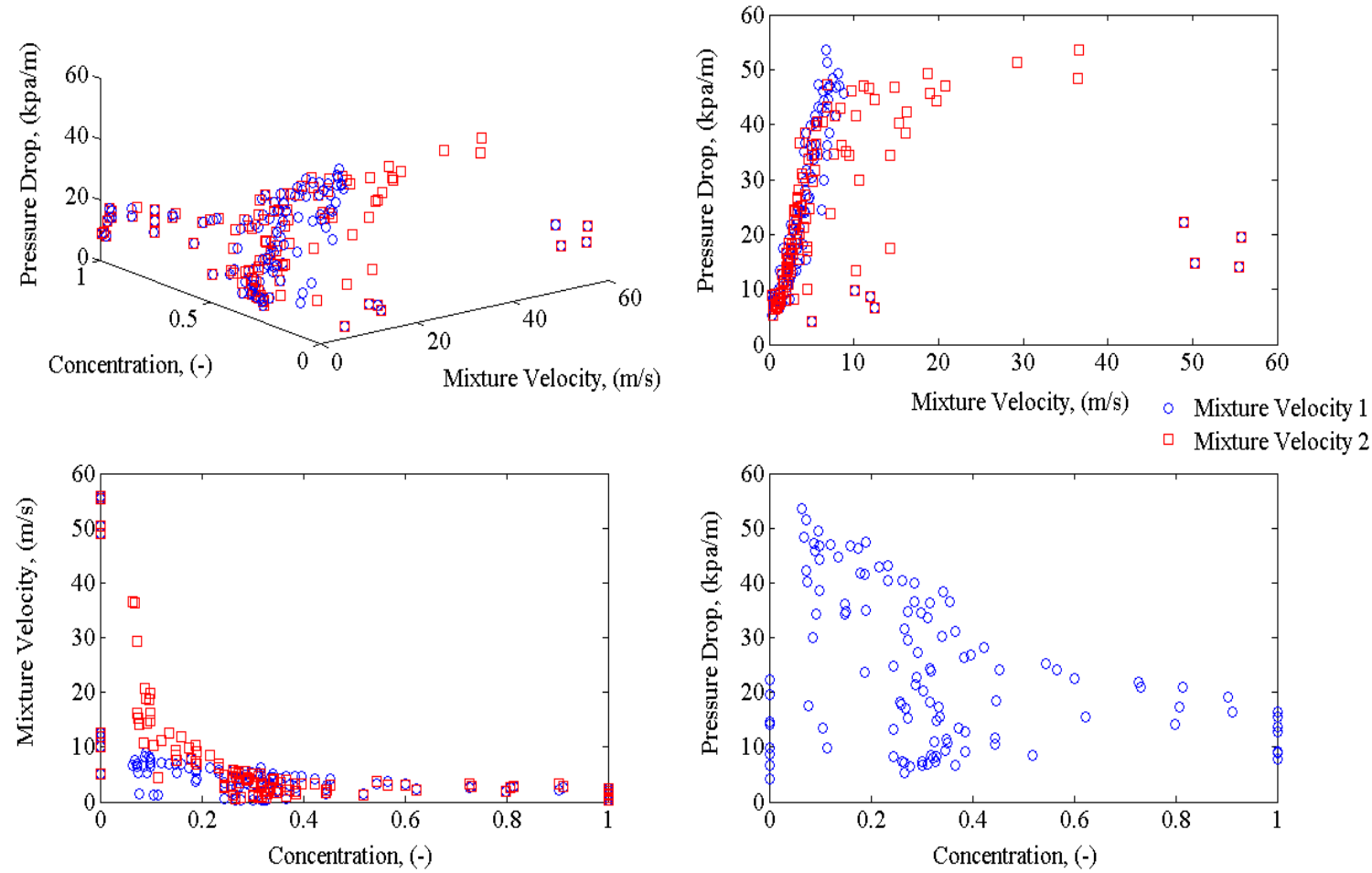

Figure 6. Pressure Drop vs. Mixture Velocity and Concentration

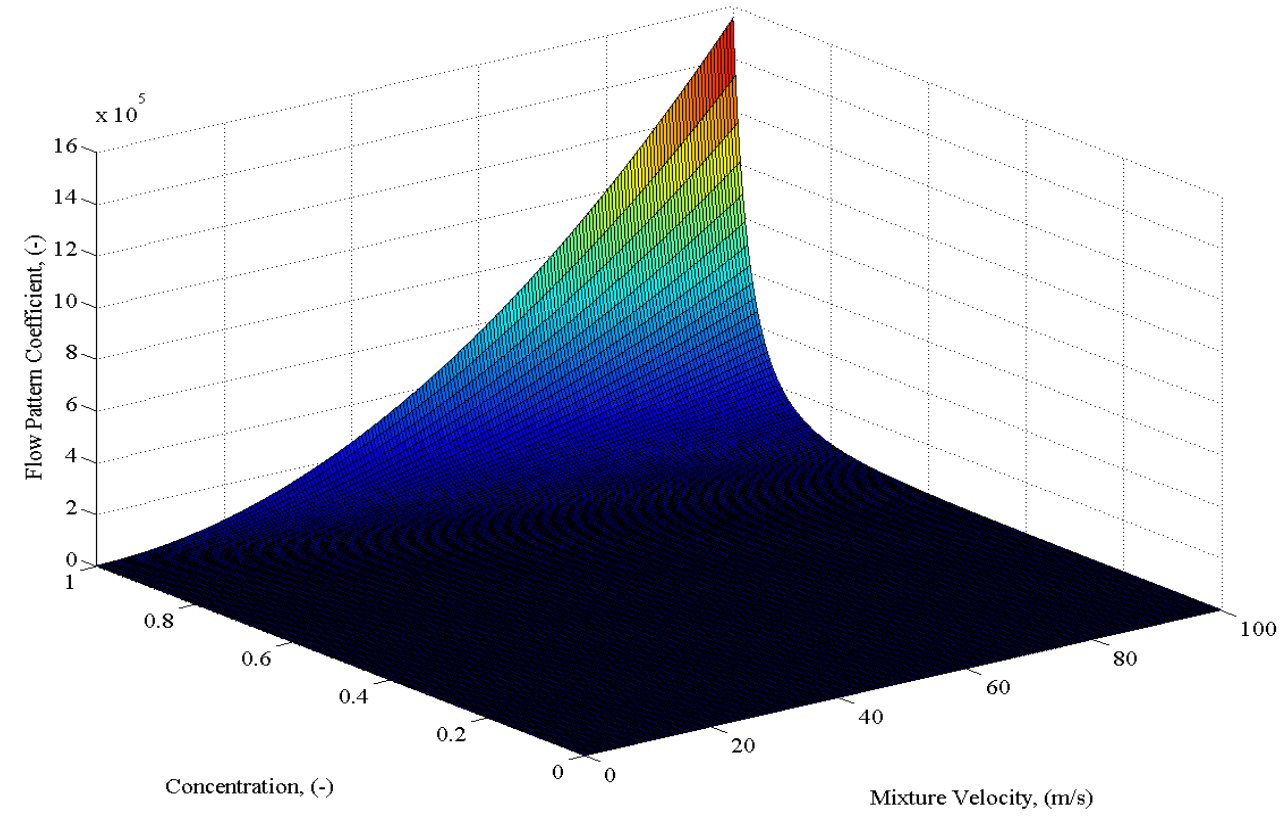

Figure 7. Flow Pattern Coefficient vs. Mixture Velocities and Concentration 

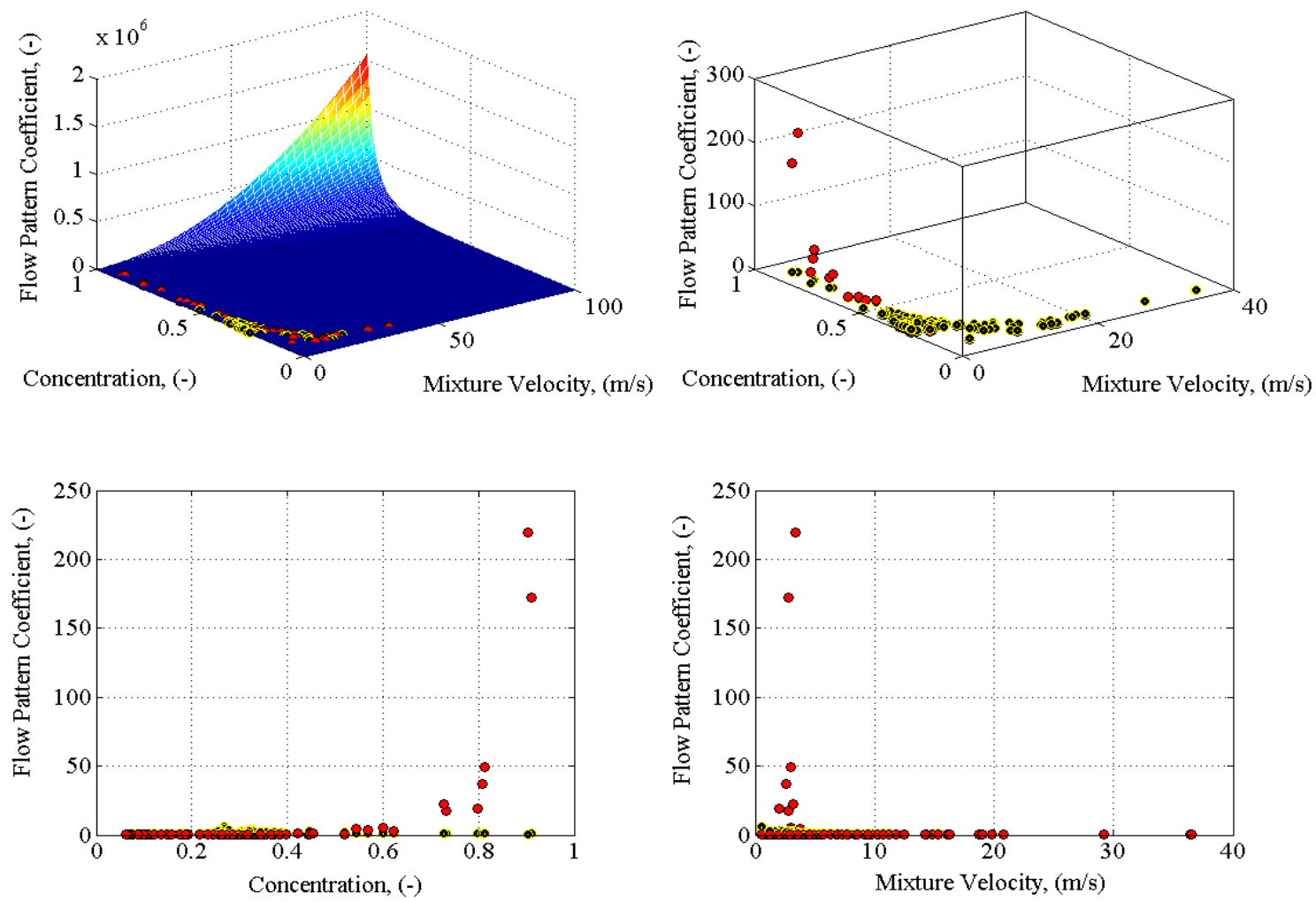

Figure 8. Flow Pattern Coefficient as a Function of Mixture Velocity and Concentration with Experimental Data

Furthermore, this fundamental equation for the Fp can be more generalized by including the channel dimension and mixture viscosity (Keska et al. ${ }^{5,6,7,8)}$ ). This could then be transferred to the following expression:

$$
F p=\frac{1}{E}\left(\frac{v_{m}}{v_{m}}\right)^{2}\left(c_{v}\right)^{F} D^{2}
$$

where $\mathrm{E}$ and $\mathrm{F}$ are constants, which could be found experimentally.

The aim of the conducted experiments is likewise to find the optimal values of the constants $\mathrm{E}$ and $\mathrm{F}$ for the fixed conditions. This should be done with the aim of minimizing the differences between the theoretical and experimental values of the pressure gradient. The preliminary analysis of experimental data produces the following Fp expressions:

$$
F p=\frac{1}{110000}\left(\frac{v_{m}}{v_{m}}\right)^{2}\left(c_{v}\right)^{3.5} D^{2} \text {; }
$$

The graphical representations of the equation are surface images, which indicate that the flow pattern coefficient for the heterogeneous mixture flow of air-water in a horizontal channel is a function of in-situ mixture velocity and concentration, what is illustrated in Figures 8. The marked red points indicate the simulated values and the yellow points indicate the experimental values. Significant differences are noted when the concentration values are above 0.6. The best results are found for Equation 19, which provides the best fit for the experimental data when in-situ concentration values are below 0.6. 


\section{Conclusions}

Based on the experimental research conducted on the air-water mixture flow in the full range of spatial in-situ concentrations (0-1) and mixture velocities $(0 \mathrm{~m} / \mathrm{s}$ to $60 \mathrm{~m} / \mathrm{s})$ in a horizontal square minichannel, the following conclusions can be drawn.

(1) Experimental data for pressure, velocity, and concentration were collected in an experimental system. For data verification, several different concomitant measurement systems were used successfully, including the measurement of in-situ spatial concentration using both capacitive and conductive systems. The experimental results show that both capacitive and conductive systems are fully concomitant with respect to spatial concentration.

(2) Flow pattern phenomena have a significant impact on two-phase flow, especially the length pressure gradient. These phenomena cause significant differences between calculated and experimental values. Incorporating the flow pattern phenomena into a model of pressure drop, through the use of the flow pattern coefficient, significantly reduces this difference. This is a function of in-situ parameters such as mixture velocity, viscosity, and concentration.

\section{Nomenclature}

$X^{2} \quad$ Martinelli parameters

$\phi_{l}^{2} \quad$ two-phase flow multiplier for liquid only

$\phi_{g}^{2} \quad$ two-phase flow multiplier for gas only

C constant factor

Re Reynolds number

$\mu_{L} \quad$ viscosity of liquid

$\sigma \quad$ surface tension

U superficial velocity

$\begin{array}{ll}\frac{\Delta P}{\Delta L} & \text { length pressure drop } \\ h & \text { energy loss } \\ v & \text { in-situ velocity } \\ F p & \text { flow pattern coefficient } \\ & \\ \mathrm{D} & \text { channel diameter } \\ c_{v} & \text { concentration } \\ \mathrm{A} & \text { cross-sectional area }\end{array}$

\section{Subscripts}

$\begin{array}{ll}\mathrm{m} & \text { mixture flow } \\ \mathrm{g} & \text { gas only } \\ \mathrm{l} & \text { liquid only } \\ \mathrm{w} & \text { water only } \\ \mathrm{a} & \text { air only }\end{array}$




\section{References}

1. Lockhart, R. W., and Martinelli, R. C., 1949, "Proposed Correlation of Data for Isothermal Two-Phase TwoComponent Flow in Pipes," Chemical Engineering Progress, 45, pp. 39-48.

2. Lee, H. J., and Lee, S. Y., 2001, "Pressure Drop Correlations for Two-Phase Flow within Horizontal Rectangular Channels with Small Heights," International Journal of Multiphase Flow, 27, pp. 783-796.

3. Lowry, B., and Kawaji, M., 1988, "Adiabatic Vertical Two-Phase Flow in Narrow Flow Channels," American Institute of Chemical Engineers Symposium Series, 84 (263), pp. 133-139.

4. Wambsganss, M. W., Jendrzejczyk, J. A., France, D. M., and Obot, N. T., 1992, "Frictional Pressure Gradients in Two-Phase Flow in A Small Horizontal Rectangular Channel," Exp. Thermal Fluid Sci., 5, pp. 40-56.

5. Triplett, K. A., Ghiaasiaan, S. M., Abdel-Khalik, S. I., and McCord, B. N., 1999, "Gas-Liquid Two-Phase Flow in Microchannels Part II: Void Fraction And Pressure Drop," International Journal of Multiphase Flow, 25, pp. 337-410.

6. Zhao, T. S., and Bi, Q. C., 2001, "Pressure Drop Characteristics of Gas-Liquid Two-Phase Flow in Vertical Miniature Triangular Channels," International Journal of Heat and Mass Transfer, 44, pp. 2523-2534.

7. Keska, J. K., 2007 - 2008, "Personal Communication," University of Louisiana, Lafayette.

8. Keska, J. K., and Wang, G., 2006, "Pressure Gradient Calculation for Air-Water Heterogeneous Mixture Flow in A Small Square Horizontal Channel Based on the In-Situ Parameters And Flow Pattern Coefficient," Experimental Thermal and Fluid Science, 30, pp. 403-413.

9. Keska, J. K., and Simon, W. E., 2006, "Incorporation of Flow Pattern Phenomena Into The Study of Advanced Micro Cooling Modules," Proceedings of IMECE2006, Nov. 5-10, Chicago, IL, USA.

10. Keska, J. K., and Simon, W. E., 2006, "In Search Of Physical Parameters Influenced by Flow Patterns in A Heterogeneous Two-Phase Mixture in Microchannels Using Concomitant Measurements," Int. J. Multiphase Flow, 32, pp. 483-498.

11. Keska, J. K., 2008, "Progress in Analysis of Two-Phase Flow," AIP Conference Proceedings, 969, pp. 985-992.

12. Keska, J. K., and Shin, H., 2003, "Web Driven Experimentation for Two-Phase Flow," Proceedings of the 2003 ASEE Gulf-Southwest Annual Conference, The University of Texas at Arlington.

Chengyi Ma,

Chengyi Ma is a graduate student in the University of Louisiana, Lafayette, Department of Mechanical Engineering. His research interests are in the areas of fluids, thermal science, control systems and computer-aided measurement systems

JERRY K. KESKA, D. Sc. Eng.

Dr. Keska is an Associate Professor and member of the Graduate Faculty in the University of Louisiana, Lafayette, Department of Mechanical Engineering. Although most of his experience is from academia, he has had employment in private industry (Copeland Corporation, Technicon Instruments) and governmental laboratories (Pacific Northwest Laboratory, Argonne National Laboratory). His research interests are in the areas of Micro-ElectroMechanical Systems (MEMS), fluid dynamics of complex heterogeneous dispersals (multiphase, slurries), tribology, micro heat exchangers with phase transition, computer-aided measurement systems and instrumentation, electromagnetic sensors, turbulence and flow pattern phenomena in dispersals, and deterministic and random signal analysis, processing and validation. His work is disseminated in more than 100 refereed technical journal and conference publications, including books and monographs, and more than 20 patents.

Proceedings of the 2009 ASEE Gulf-Southwest Annual Conference Baylor University

Copyright (C 2009, American Society for Engineering Education 